\title{
Genetic diversity of Plasmodium vivax population before elimination of malaria in Hainan Province, China
}

\author{
Yu-Chun Li, Guang-Ze Wang ${ }^{*}$, Feng Meng, Wen Zeng, Chang-hua He, Xi-Min Hu* and Shan-Qing Wang ${ }^{*}$
}

\begin{abstract}
Background: Hainan Province is one of the most severe endemic regions with high transmission of Plasmodium falciparum and Plasmodium vivax in China. However, the incidence of $P$. falciparum and P. vivax has dropped dramatically since 2007 and a national elimination malaria programme (NEMP) was launched after 2010. To better understand the genetic information on P. vivax population before elimination of malaria in Hainan Province, the extent of genetic diversity of $P$. vivax isolates in Hainan Province was investigated using four polymorphic genetic markers, including $P$. vivax merozoite surface proteins $1,3 a$, and $3 \beta$ (pvmsp-1, pvmsp-3a, and pvmsp-3 $\beta$ ) and circumsporozoite protein ( $p v c s p)$.

Methods: Isolates of P. vivax ( $n=27)$ from Hainan Province were collected from 2009 to 2010 and pvmsp-1 and pvcsp were analysed by DNA sequencing, respectively. Using polymerase chain reaction-restriction fragment length polymorphism were analysed in pvmsp-3a, and pvmsp-3 $\beta$.

Results: The DNA sequencing analysis on pvmsp1 revealed that there were three allele types: Salvador-1 (Sal-1), Belem and recombinant (R) types. Among them, Sal-1 type was a dominant strain with eight variant subtypes (88.9\%), whereas R- (3.7\%) and Belem-type strains (7.4\%) had one variant subtypes, respectively. All the isolates carried pvcsp with VK210 type accounting for 85.2\% (23/27 isolates) and VK247 type accounting for 14.8\% (4/27). Only type A and type $B$ alleles were successfully amplified in pvmsp-3a gene, and a high level of polymorphism was observed in pvmsp-3a. Considering pvmsp-3 $\beta$ gene, type A was the predominant type in 17 isolates (63\%), whereas type B was dominant in only ten isolates (37\%).

Conclusion: The present data indicate that there was high degree of genetic diversity among $P$. vivax population in Hainan Province of China during the pre-elimination stage of malaria, with 26 unique haplotypes observed among 27 samples.
\end{abstract}

Keywords: Plasmodium vivax, pvmsp-1, pvcsp, pvmsp-3a, pvmsp-3ß, Hainan province, Elimination malaria, China

\section{Background}

Plasmodium vivax is one of the most widespread species of human malarial parasites in Asia, Central and South America, the Middle East, and parts of Africa. The malarial infection causes substantial economic loss around the world, and billions of people are at risk of malarial infection [1,2]. In China, the situation has changed quickly and reported cases of malaria have declined

\footnotetext{
*Correspondence: wangguangze63@126.com; huximin372@sohu.com; wangsqkevin@163.com

Hainan Provincial Centre for Disease Control and Prevention, Haikou 570203,
} China cided to embark upon the National Malaria Elimination Programme (NMEP) with a goal of eliminating malaria by 2015 in the majority of regions, with the exception of the border region in Yunnan Province, and to completely eliminate malaria from PR China by 2020.

Hainan Province was one of the most severe endemic areas with high transmission of Plasmodium falciparum and $P$. vivax. There were no reports of autochthonous $P$. falciparum malarial cases before the implementation of NMEP; however, $P$. vivax was still transmitted $[5,6]$. 
Before achieving the goal of eliminating malarial infection in Hainan Island, it is essential to understand the diversity of autochthonous malaria and to predict the origin and the spread of parasite variants within and between populations. However, so far the population structure of $P$. vivax is less well understood and the population genetics of $P$. vivax has not been systematically studied in Hainan Province, before the start of elimination campaigns [7]. In this study, the population diversity of $P$. vivax isolates from Hainan Province was evaluated using four polymorphic markers.

\section{Methods}

\section{Study area}

The study was conducted in the main island of the Hainan Province, which is located at north latitude $18^{\circ} 10^{\prime}-20^{\circ} 10^{\prime}$ and east longitude $108^{\circ} 37^{\prime}-111^{\circ} 03^{\prime}$, in southern China (Figure 1). The Province is characterized by mountainous and hilly landscape. The tropical monsoon and marine climate produce high temperatures and rich rainfall, which is suitable for malaria transmission [8]. Climatic and ecological conditions of this area make the environment favourable for mosquito breeding, and the main malaria vector are Anopheles dirus and Anopheles minimus.

\section{Patients and sample collection}

Blood samples were collected from patients in Hainan Province who had symptoms of malaria from June 2009 to December 2012. The patients with malaria were diagnosed by blood smears and rapid diagnostic tests (RDTs) in township or county hospitals, before treatment [9]. All the samples were transported to Hainan Provincial Centre for Disease Control and Prevention (Hi CDC) for further confirmation by polymerase chain reaction (PCR) method. Of 226 reported malaria cases found by these methods, 37 cases were autochthonous $P$. vivaxinfected patients, confirmed from malaria patient questionnaires. Two $\mathrm{ml}$ of whole blood sample was collected in EDTA and stored at $-20^{\circ} \mathrm{C}$ until DNA extraction. This study was approved by the Ethics Committee of Hainan Provincial Center for Disease Control and Prevention (Hi CDC), China.

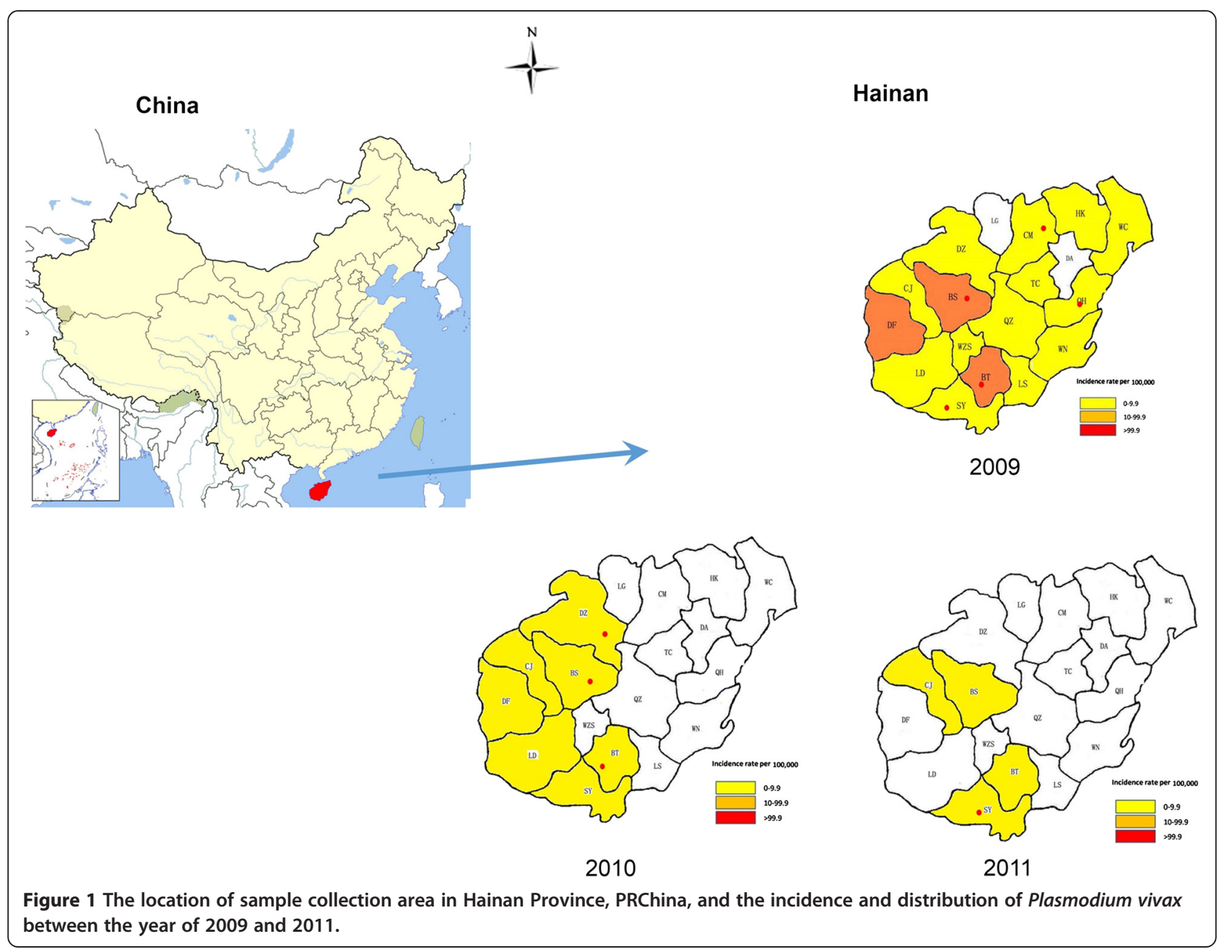




\section{DNA extraction}

Plasmodium vivax genomic DNA was extracted from $80 \mu \mathrm{l}$ of each infected blood sample using DNA blood kit following the manufacturer's instructions (Qiagen, Germany) with minor modifications. The DNA was dissolved in TE buffer (10 mM Tris- $\mathrm{HCl}, \mathrm{pH} 8.0,0.1 \mathrm{M}$ EDTA) and stored at $-20^{\circ} \mathrm{C}$ until use. The quality of total DNA was analysed by running $5 \mu \mathrm{L}$ of each DNA sample on a $1.0 \%$ agarose gel stained with ethidium bromide and visualized with UV illumination.

\section{PCR amplification of pvmsp-3a, pvmsp-3 $\beta$, pvmsp-1, and pvcsp genes}

To amplify the $p v m s p-3 \alpha, p v m s p-3 \beta$, pvmsp-1, and $p v c s p$ genes, a nested PCR amplification method was used following previously reported protocols with some minor modifications $[10,11]$. Oligonucleotide primers and cycling conditions are listed in Table 1. All amplification reactions were carried out in a total volume of $50 \mu \mathrm{L}$ containing $20 \mu \mathrm{l}$ of $\mathrm{ddH}_{2} \mathrm{O}, 2.0 \mu \mathrm{l}$ of each primer $(10 \mathrm{pM})$, $25 \mu \mathrm{l} 2 \times$ pfuTaq mixture, which contained $0.1 \mathrm{U}$ Pfu polymerase $/ \mu \mathrm{l}, 500 \mu \mathrm{M}$ dNTP each, $50 \mathrm{mM}$ Tris- $\mathrm{HCl}$ (pH 8.7), $20 \mathrm{mM} \mathrm{KCl}, 4 \mathrm{mM} \mathrm{MgCl}$, other stabilizing and strengthening reagents, following the manufacturer's instructions (Tiangen, China). Primary amplification reactions were initiated with the addition of $2.0 \mu \mathrm{l}$ of template genomic DNA prepared from the blood samples; $1.0 \mu \mathrm{l}$ of the primary reaction amplification was used as template in the secondary amplification reactions. The amplified PCR products were resolved on 1.5\% agarose gel, and the sizes of the PCR products were determined using a D2000 DNA ladder (Tiangen, China).

Sequence analysis and phylogeny on pvmsp-1, pvcsp genes The nested PCR products of $p v m s p-1$, pvcsp were directly sequenced in both directions using an ABI PRISM3730 DNA sequencer by Sangon Biotech (Shanghai, China). Nucleotide or amino acid sequences obtained from the blood samples of the malaria patients in this study were compared by CLUSTAL $\mathrm{X}$ and BioEdit 5.0 programme with the following published sequences: VK210 (accession no. M28746) and VK247 (accession no. M28745) of pvcsp and Sal-I (accession no. M75674) and Belem (accession no. M60807) of pvmsp-1, respectively. Sequence relationship trees of the pvmsp-1 and pvcsp genes from the Hainan isolates and published sequences from isolates of different geographic locations of world were constructed using neighbour-joining method implemented in MEGA 3 program [12]. Bootstrap proportions were used to assess the robustness of the tree with 1,000 bootstrap replications.

$\mathrm{PCR} /$ restriction fragment length polymorphism analysis of pvmsp-3 $\alpha$ and pvmsp- $3 \beta$ gene

For restriction fragment length polymorphism (RFLP)

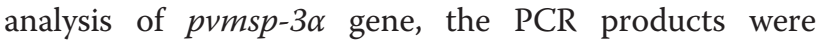
digested individually with restriction enzymes $H h a$ I and $A l u \mathrm{I}$ in $20 \mu \mathrm{l}$ reaction volumes at $37^{\circ} \mathrm{C}$ for three hours, as previously described [13]. Briefly, all digestion reactions were carried out in the presence of $10.0 \mu \mathrm{l} \mathrm{PCR}$ product, $2.0 \mu \mathrm{l}$ of ddH2O, $1.0 \mu \mathrm{l}$ of enzymes Hha I or Alu I $(5 \mathrm{U} / \mu \mathrm{l})$, and $2.0 \mu \mathrm{l}$ of buffer according to the

Table 1 Primers for amplication on pvmsp-3a, pvmsp-3 $\beta$, pvmsp-1, and pvcsp genes

\begin{tabular}{|c|c|c|}
\hline Gene Primers* & Squencen $\left(5^{\prime}-3^{\prime}\right)$ & PCR cycling conditions** \\
\hline \multirow[t]{2}{*}{$\operatorname{pvcsp}(\mathrm{N} 1)$} & F:5'-ATGTAGATCTGTCCAAGGCCATAAA-3' & $95^{\circ} \mathrm{C} 3 \mathrm{~min} /\left[94^{\circ} \mathrm{C} 30 \mathrm{~s}, 58^{\circ} \mathrm{C} 30 \mathrm{~s}, 72^{\circ} \mathrm{C} 1.5 \mathrm{~min}\right] \times 30$ cycles, $72^{\circ} \mathrm{C} 5 \mathrm{~min}$ \\
\hline & R:5'-TAATTGAATAATGCTAGGACTAACAATATG-3' & \\
\hline \multirow[t]{2}{*}{$\operatorname{pvcsp}(\mathrm{N} 2)$} & F:5'-CCAGATGACGAGGAAGGAGATGC-3' & $95^{\circ} \mathrm{C} 3 \mathrm{~min} /\left[94^{\circ} \mathrm{C} 30 \mathrm{~s}, 58^{\circ} \mathrm{C} 30 \mathrm{~s}, 72^{\circ} \mathrm{C} 1 \mathrm{~min}\right] \times 35$ cycles, $72^{\circ} \mathrm{C} 5 \mathrm{~min}$ \\
\hline & R:5'-TCTTTCACAGACTITTCATTTGGG-3' & \\
\hline \multirow[t]{2}{*}{ pvmsp-1(N1) } & F:5'-GAGCCCTACTACTTGATGGTCC-3' & $95^{\circ} \mathrm{C} 3 \mathrm{~min} /\left[94^{\circ} \mathrm{C} 30 \mathrm{~s}, 58^{\circ} \mathrm{C} 30 \mathrm{~s}, 72^{\circ} \mathrm{C} 1 \mathrm{~min}\right] \times 35$ cycles, $72^{\circ} \mathrm{C} 5 \mathrm{~min}$ \\
\hline & R:5'-CCTTCTGGTACAGCTCAATG-3' & \\
\hline \multirow[t]{2}{*}{ pvmsp-3a(N1) } & F:5'-CAGCAGACACCATTTAAGG-3' & $95^{\circ} \mathrm{C} 3 \mathrm{~min} /\left[94^{\circ} \mathrm{C} 30 \mathrm{~s}, 54^{\circ} \mathrm{C} 30 \mathrm{~s}, 68^{\circ} \mathrm{C} 2.5 \mathrm{~min}\right] \times 30$ cycles, $68^{\circ} \mathrm{C} 5 \mathrm{~min}$ \\
\hline & R:5'-CCGTTTGTTGATTAGTTGC-3' & \\
\hline \multirow[t]{2}{*}{ pvmsp-3a(N2) } & F:5'-GACCAGTGTGATACCATTAACC-3' & $95^{\circ} \mathrm{C} 3 \mathrm{~min} /\left[94^{\circ} \mathrm{C} 30 \mathrm{~s}, 55^{\circ} \mathrm{C} 30 \mathrm{~s}, 68^{\circ} \mathrm{C} 2.5 \mathrm{~min}\right] \times 40$ cycles, $68^{\circ} \mathrm{C} 5 \mathrm{~min}$ \\
\hline & R:5'-ATACTGGTTCTTCGTCTTCAGG-3' & \\
\hline \multirow[t]{2}{*}{ pvmsp-3 $\boldsymbol{\beta}(\mathrm{N} 1)$} & F:GTATTCTTCGCAACACTC & $95^{\circ} \mathrm{C} 3 \mathrm{~min} /\left[94^{\circ} \mathrm{C} 30 \mathrm{~s}, 54^{\circ} \mathrm{C} 30 \mathrm{~s}, 68^{\circ} \mathrm{C} 2.5 \mathrm{~min}\right] \times 30$ cycles, $68^{\circ} \mathrm{C} 5 \mathrm{~min}$ \\
\hline & R:CTTCTGATGTTATTTCCAG & \\
\hline \multirow[t]{2}{*}{ pvmsp-3 $\boldsymbol{\beta}(\mathrm{N} 2)$} & F:CGAGGGGCGAAATTGTAAACC & $95^{\circ} \mathrm{C} 3 \mathrm{~min} /\left[94^{\circ} \mathrm{C} 30 \mathrm{~s}, 55^{\circ} \mathrm{C} 30 \mathrm{~s}, 68^{\circ} \mathrm{C} 2.5 \mathrm{~min}\right] \times 40$ cycles, $68^{\circ} \mathrm{C} 5 \mathrm{~min}$ \\
\hline & R:GCTGCTTCTITGGAAAGG & \\
\hline
\end{tabular}

$\mathrm{N} 1=$ Nest 1 (Primary) reaction; N2 = Nest 2 (Secondary) PCR reaction.

${ }^{*} \mathrm{~F}=$ Forward primer; $\mathrm{R}=$ Reverse primer. The reference sources of the primers are indicated.

**The cycling conditions have been modified in the present work.

The two columns indicate conditions for the primary and secondary amplification reaction. 
manufacturer's instructions (TaKaRa, Japan). After electrophoresis on $2.5 \%$ agarose gel, the enzyme-digested fragments were visualized under UV illumination. The sizes of the digested fragments were estimated using 50 bp and D2000 ladder of molecular weight markers. The results were recorded and analysed on a Gel Doc XR image analyzer using Imagine Lab 2.0 software (Bio-Rad, USA). For RFLP analysis of $p v m s p-3 \beta$ gene, the reaction condition and ingredient of mixture except enzyme Pst I were the same as the RFLP analysis of pvmsp-3 $\alpha$ gene.

\section{Results}

\section{pvMSP-1 gene analysis and clustering}

All 27 isolates from Hainan were successfully amplified for pvmsp-1 gene. Sequence analyses of the PCR products showed that the isolates could be divided into three types: Sal-I type, Belem type and recombination (R) type (Figure 2). Diverse non-synonymous substitutions were shown and distributed into nine different sequence types. Subtype A and subtype B showed the continually amino acid sequence substitution (DKKLLKEYE) specific to the Belem type. In other Sal-1 subtypes, seven amino acid substitutions (V/A, I/T, A/T, A/V, E/Q, N/K, $\mathrm{T} / \mathrm{N}$ ) were identified at different positions and only one glutamine or proline or histidine insertion. Comparing sequence with Belem reference, subtype I was classified as the Belem type and contained 14 poly-Q repeats and the amino acid sequence MKKELLDQYK specific to the Sal I type rather than the DKKLLKEYE specific to the Belem type. Comparison of the Sal-1 and Belem strains detected only one subtype (subtype $\mathrm{H}$ ) of the recombinant strain, which displayed a forward and reverse sequence pattern similar to the Sal I and Belem strains, respectively. In addition to these sources of diversity, 13 glutamine residue repeats were present in this recombinant subtype.

In those types, Salvador-1 (Sal-1) was dominant strain and seven variant subtypes for the Sal-I type (88.9\%). Rtype $(3.7 \%)$ or Belem-type $(7.4 \%)$ only had one variant subtypes, respectively. In Sal-I subtypes, subtype A and subtype $\mathrm{F}$ were the most prevalent and accounted for $22.2 \%$. The frequencies of others subtypes variants were evenly distributed among the variants.

A phylogenetic tree of the pvmsp-1 was constructed using amino acid sequences from the Hainan isolates and 54 published pvmsp-1 sequences obtained from the isolates of different geographic locations of world (19 from different provinces of China, one from Bangladesh, one from Azerbaijan, four from India, one from Iran, one from Papua New Guinea, three from Brazil, three from Mexico, and four from Thailand including the SalI strain and Belem reference strains). This analysis grouped the $P$. vivax Hainan population into two major clusters (Sal-I type and R-type) with different subtypes in each group (Figure 3). All of the P. vivax isolates examined in this study showed extremely high identity (range from 99 to 96\%) with the isolates from different geographic locations of world. Subtype A and subtype B identified in this study were similar (99\%) to India (Punjab) isolate (CAD41952), respectively. Subtype C and subtype $\mathrm{F}$ had extensive similarity (98\%) with the Thailand isolate (BAA18985). Subtype D and subtype E were similar to the Thailand isolate (BAA18985), with 98 and 99\% sequence homology, respectively. Similarity between subtype $\mathrm{G}$ and the Mexico isolate (AFU34378) was 98\%. The recombinant strain (subtype H) had similarity (99\%) with the Mexico isolate (AFU 34374) and Belem strain (subtype I) also had extreme similarity (96\%) with the Mexico isolate (AFU34366).

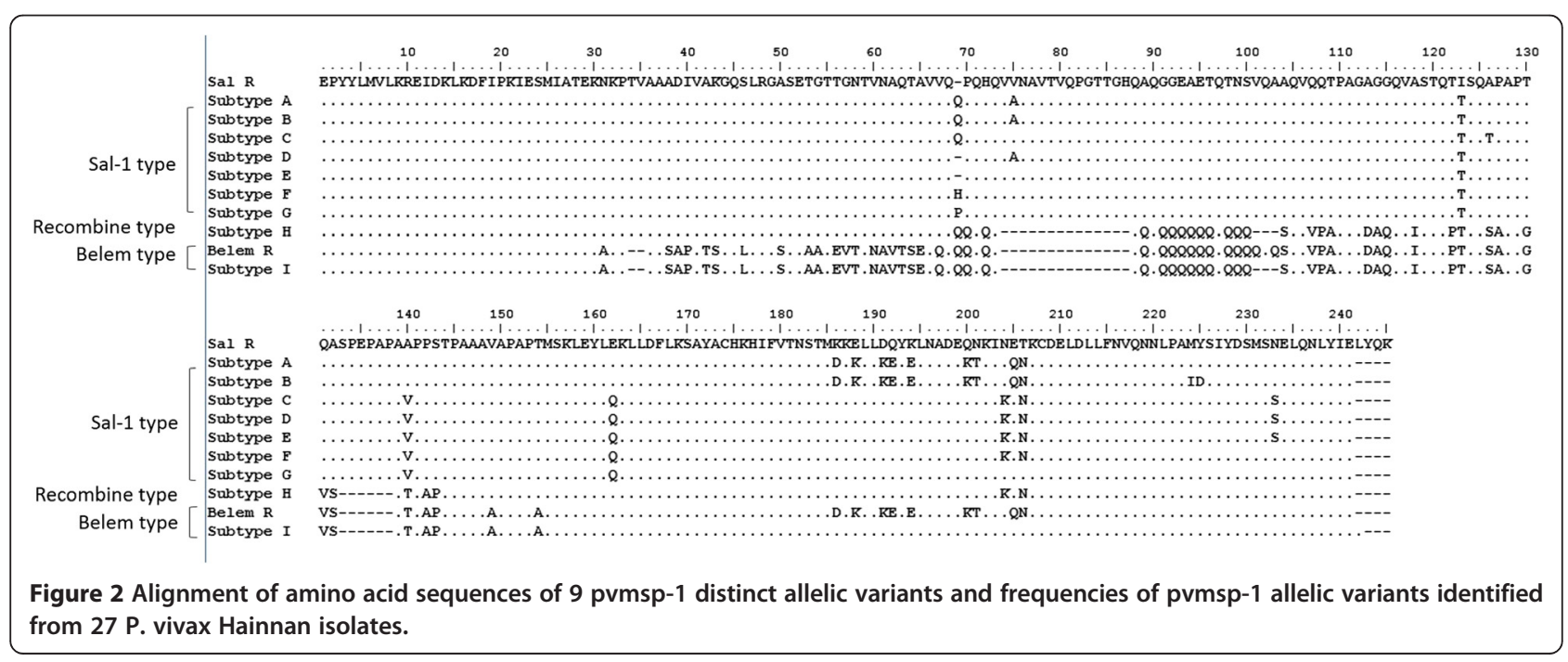




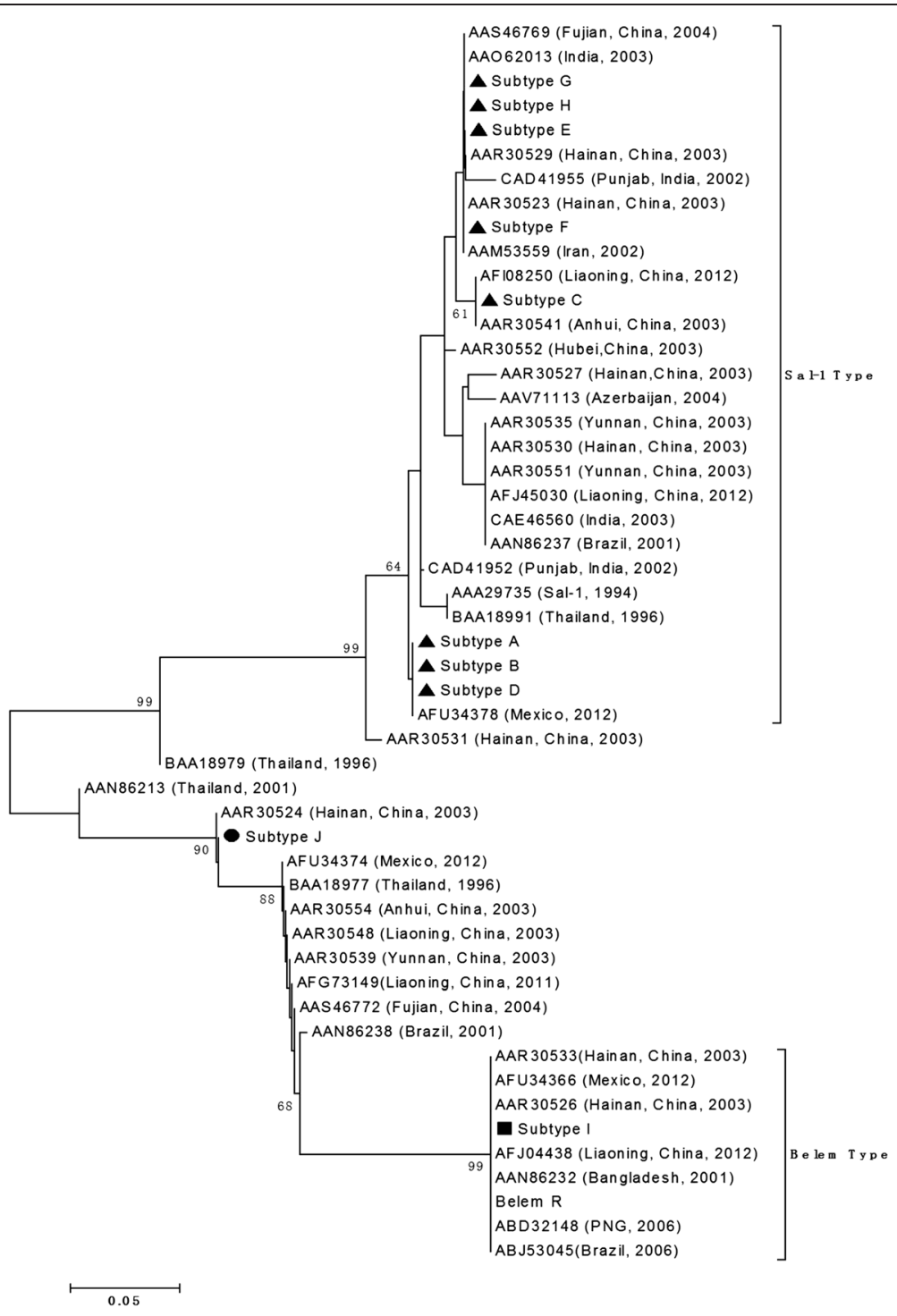

Figure 3 Phylogenetic analysis of the P. vivax MSP-1 gene. The phylogeny tree was constructed with the neighbor-joiningmethod using the MEGA 3 program.

\section{pvcsp gene analysis and clustering}

The classic $P$. vivax VK210 strain has a $p v c s p$ sequence that includes a GDRA(A/D)GQPA amino acid repeat. A variant form, VK247, later identified in Thailand, has an ANGAGNQPG amino acid repeat in the tandem repeat amino acid region [14]. Sequences of $\operatorname{csp}$ gene revealed that they were single infections in this study, not mixed infection. The majority of the isolates $(85.2 \%, 23 / 27)$ were of the VK210 type while VK247 type accounted for $14.8 \%(4 / 27)$. Depending on the type and number of repeat motif, all of the DNA sequences belonged to VK210 type with nine distinct variants, and to VK247 type with four variants, whereas no $P$. vivax-like types were detected within these isolates. The frequency distribution of the 13 subtypes is shown in Figure $4 \mathrm{a}$ and b.
Of the 13 subtypes, the most prevalent sequence variant was subtype F $(25.9 \%, 7 / 27)$, followed by subtype A (18.5\%, 5/27), subtype E and subtype G (11.1\%, 3/27). The remaining nine subtypes of $p v c s p$ gene were evenly distributed among these isolates.

All variants started with the same pre-repeat sequence (KLKQP Region). The isolates displayed variations in the central peptide repeat motifs GDRA (A/D) GQPA or ANGAGNQPG with alternations of the repeating units. Each amino acid sequence group was representative of one or more strains. A phylogenetic tree of the pvcsp sequences was constructed using the neighbour-joining method based on the amino sequences from Hainan isolates in this study, and 51 published pvcsp sequences from the isolates of different geographic locations of 


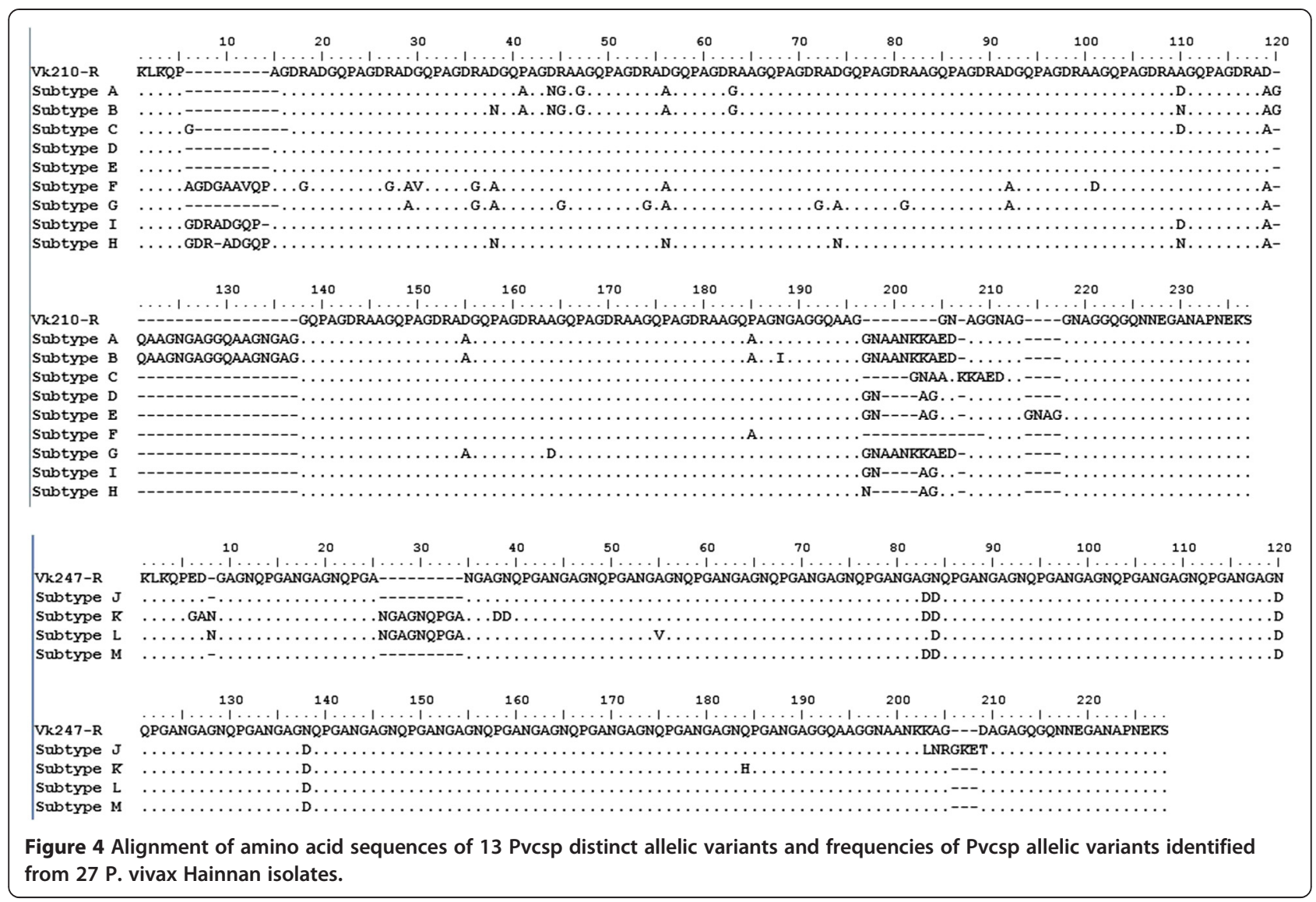

world (five from China, one from Indonesia, three from India, seven from Iran, two from Myanmar, one from North Korea, four from south Korean, one from Papua New Guinea (PNG), one from the Solomon Islands, three from Vietnam, one from Honduras, one from Gabon, eight from Colombia, seven from Brazil, one from Philippines, two from Thailand, one from Bangladesh, one from Mauritania and two from Myanmar) (Figure 5). The sequences clustered into two distinct groups for the VK210 and VK247 type. And the analysis clearly showed that all subtypes of pvcsp from Hainan isolates clustered with the VK210 type and VK247 type in the tree, respectively. Some of the P. vivax isolates examined in this study showed $100 \%$ identity with strains from other regions of China or even from other countries, including China's Tibet (AAA29534 with subtype A (VK210 type)), Mauritania (AFI80543 with subtype C (VK210 type)), Cambodia (AGN05237 with subtype D (VK210 type)). The remaining subtypes were new alleles identified in this study.

\section{PCR/RFLP analysis of the pvmsp-3a gene}

The $p v m s p-3 \alpha$ gene was successfully amplified from all the $27 P$. vivax isolates examined. Twenty-six samples of the PCR products from $P$. vivax isolates were the same size, approximately $1.9 \mathrm{~kb}$ (type A); one sample belonged to type $\mathrm{B}(\sim 1.5 \mathrm{~kb})$; no type $\mathrm{C}(\sim 1.1 \mathrm{~kb})$ or type $\mathrm{D}$ ( $\sim 500 \mathrm{bp})$ was detected. The PCR-RFLP analysis revealed a high level of polymorphism in $p v m s p-3 \alpha$ gene after the PCR products were digested with restriction enzymes Hha I and Alu I: nine (A1 to A8, B1) and 11 (H1 to H11) (Figures 6A, B). The frequency distribution of each variant is shown. In the Alu I digestion, allelic variants $\mathrm{A} 1, \mathrm{~A} 3$ and $\mathrm{A} 6$ were the most common patterns, with frequencies of $29.6,25.9$ and $14.8 \%$, respectively. Similarly, $70.4 \%$ of the $H$ haI digested samples were allele variants of $\mathrm{H} 1, \mathrm{H} 2$ and $\mathrm{H} 3$, representing 11.1, 29.6 and $29.6 \%$, respectively.

\section{PCR/RFLP analysis of the pvmsp-3 3 gene}

The $p v m s p-3 \beta$ gene was successfully amplified in 27 malaria samples and A type (1.7-2.4 kb) and B type (1.4-1.5 kb) were identified, following an earlier scheme [15]. Type A was the predominant type in 17 isolates (63\%), while Type B accounted for only ten isolates (37\%). Restriction analysis of the PCR products by Pst I revealed six variants (A1-A6) for type A allele and two variants (B1-B3) for type B allele, whereas mixed infection and undigested variants had one and eight, respectively (Figure 6C). In digestion, allelic variants PA1, PA2 


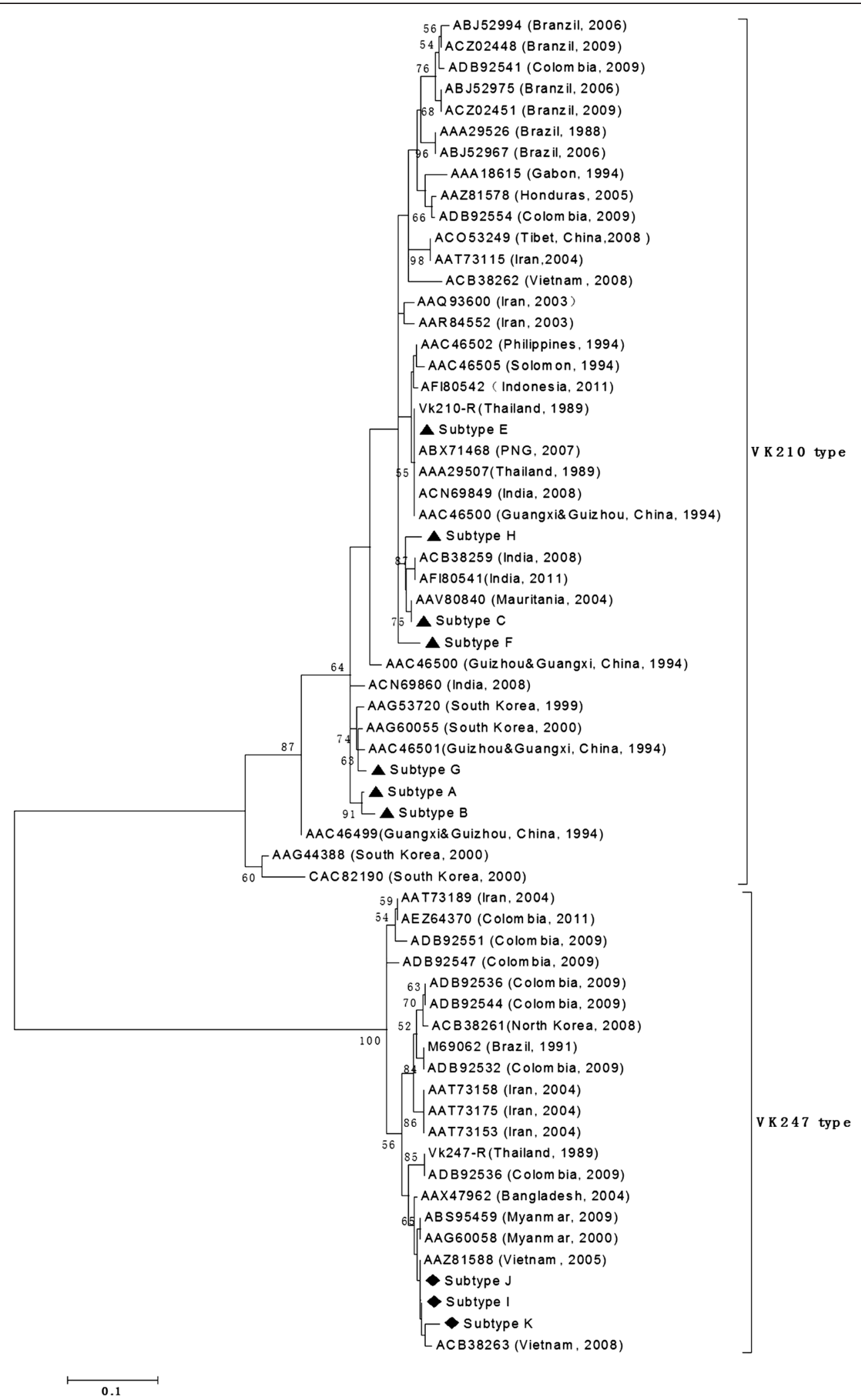

Figure 5 Phylogenetic analysis of the P. vivax CSP gene. The phylogeny tree was constructed with the neighbor-joiningmethod using the MEGA 3 program. 




and undigested were the most common patterns, with frequencies of 22.2, 18.5 and 29.6\%, respectively. Other allelic variants were distributed evenly. Mixed infection with pvmsp-3 $\beta$ was considered in four isolates when more than one PCR product of different size was detected in a single sample, or when the summed size of the restriction fragments exceeded the size of the PCR products. The variant of PM (mixed infection) have three bands, the sizes of two bands exceeded 500 bp and that of the other band was near 2,000 bp. The summed size of the restriction fragments exceeded the size of the PCR products.

\section{Haplotypes from combined pvmsp-1, pvcsp, pvmsp-3a and pvmsp-3 $\beta$ variants}

By analysing variants of the four genetic markers

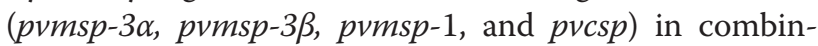
ation, results showed high diversity of the parasites with 26 genotypic patterns in Hainan Province (Table 2). Almost all haplotypes were different in every isolate. The frequency of every haplotype was $3.7 \%$ with even distribution in almost all haplotypes except variant B with haplotype A of $\mathrm{H} 3$ and $\mathrm{A} 1$ of $p v m s p-3 \alpha$, PA2 of $p v m s p$ $3 \beta$, Sal-1 of pvmsp-1, and VK210 of pvcsp, which had two members and had corresponding higher frequency (7.4\%).

\section{Discussion}

Malaria is one of the most important infectious diseases in China, and most of the autochthonous malarial cases have been reported in the southern region of China in earlier decades, including Hainan Province and Yunnan Province. Parasites, including P. falciparum and P. vivax, are prevalent in those two provinces; however, in the past ten years, malaria has been controlled in China. The autochthonous malaria cases in the corresponding endemic regions have been reduced almost to zero with the support from the Chinese Government and the dedicated efforts of healthcare professionals. Hainan Province, one of the most endemic regions with historically high transmission of $P$. falciparum, has not reported any autochthonous P. falciparum malaria case since 2010 $[16,17]$. Moreover, no P. vivax autochthonous case has been reported since 2013 [18]. Information on genetic diversity of malarial parasites is important to understand the dynamics of disease transmission, to develop targeted anti-malarial drugs, and to develop effective methods to trace the origin of infections. Furthermore, 
Table 2 Combined haplotypes and frequencies of pvmsp-3a, pvmsp-3 3 , pvmsp-1, and pvcsp from 27 vivax isolates of Hainan Province

\begin{tabular}{|c|c|c|c|c|c|c|}
\hline \multirow{2}{*}{$\begin{array}{l}\text { Allelic } \\
\text { variants }\end{array}$} & \multicolumn{2}{|c|}{ pvmsp-3a } & \multirow{2}{*}{$\begin{array}{l}\text { pvmsp-3 } \\
\text { Pst I }\end{array}$} & \multirow[t]{2}{*}{ pvmsp-1 } & \multirow[t]{2}{*}{ pvcsp } & \multirow[t]{2}{*}{ Numbers } \\
\hline & Alu I & Hhal & & & & \\
\hline $\mathrm{A}$ & $A 2$ & $\mathrm{H} 1$ & PB1 & $\mathrm{R}-\mathrm{H}$ & G-VK210 & $3.70 \%$ \\
\hline B & A2 & $\mathrm{H} 1$ & PU & S-F & E-VK210 & $3.70 \%$ \\
\hline$C$ & A2 & $\mathrm{H} 1$ & PU & S-A & E-VK210 & $3.70 \%$ \\
\hline D & A6 & $\mathrm{H} 2$ & PA1 & S-E & K-VK247 & $3.70 \%$ \\
\hline E & A6 & $\mathrm{H} 2$ & PA1 & $\mathrm{S}-\mathrm{C}$ & A-VK210 & $3.70 \%$ \\
\hline $\mathrm{F}$ & A6 & H9 & PU & B-I & A-VK210 & $3.70 \%$ \\
\hline G & A6 & $\mathrm{H} 10$ & PA6 & S-F & G-VK210 & $3.70 \%$ \\
\hline $\mathrm{H}$ & A5 & $\mathrm{H} 11$ & PM & $S-G$ & C-VK210 & $3.70 \%$ \\
\hline 1 & A1 & $\mathrm{H} 3$ & PA2 & S-A & F-VK210 & $7.41 \%$ \\
\hline J & $\mathrm{A} 1$ & $\mathrm{H} 3$ & PA2 & S-D & H-VK210 & $3.70 \%$ \\
\hline K & B1 & $\mathrm{H} 7$ & PB2 & S-D & J-VK247 & $3.70 \%$ \\
\hline L & $\mathrm{A} 1$ & $\mathrm{H} 3$ & PA7 & S-A & F-VK210 & $3.70 \%$ \\
\hline M & A3 & $\mathrm{H} 2$ & PU & S-F & M-VK247 & $3.70 \%$ \\
\hline $\mathrm{N}$ & A8 & H6 & PA5 & $\mathrm{R}-\mathrm{H}$ & G-VK210 & $3.70 \%$ \\
\hline O & A4 & $\mathrm{H} 8$ & PA3 & S-F & I-VK247 & $3.70 \%$ \\
\hline P & $\mathrm{A} 1$ & $\mathrm{H} 3$ & PU & S-A & F-VK210 & $3.70 \%$ \\
\hline Q & $\mathrm{A} 1$ & $\mathrm{H} 3$ & PA2 & S-B & F-VK210 & $3.70 \%$ \\
\hline $\mathrm{R}$ & A7 & H5 & PU & S-F & E-VK210 & $3.70 \%$ \\
\hline S & A3 & $\mathrm{H} 4$ & PU & S-E & D-VK210 & $3.70 \%$ \\
\hline $\mathrm{T}$ & A1 & $\mathrm{H} 3$ & PB3 & S-A & F-VK210 & $3.70 \%$ \\
\hline U & A3 & $\mathrm{H} 2$ & PA1 & S-C & B-VK210 & $3.70 \%$ \\
\hline V & A6 & $\mathrm{H} 2$ & PA1 & $S-C$ & A-VK210 & $3.70 \%$ \\
\hline W & $\mathrm{A} 1$ & $\mathrm{H} 3$ & PA2 & S-A & F-VK210 & $3.70 \%$ \\
\hline$x$ & A3 & $\mathrm{H} 2$ & PA1 & $S-C$ & A-VK210 & $3.70 \%$ \\
\hline Y & A3 & $\mathrm{H} 2$ & PU & S-F & L-VK247 & $3.70 \%$ \\
\hline Z & A3 & $\mathrm{H} 2$ & PA1 & $S-C$ & A-VK210 & $3.70 \%$ \\
\hline
\end{tabular}

A: The allelic type of pvmsp-3a was based on the fragment sizes of Alul -digested PCR products; $\mathrm{H}$ : The allelic type of pvmsp-3a was based on the fragment sizes of Hhal-digested PCR products; PA: The allelic type of pvmsp- $3 \beta$ was based on the A type fragment sizes of Pstl-digested PCR products; PB: The allelic type of pvmsp-3 $\beta$ was based on the B type fragment sizes of Pst I-digested PCR products; PU: Undigest fragment; S: Sal-I type; B: Belem type; R: Recombination type of pvmsp-1.

knowledge of parasite population genetics would be useful in designing and monitoring strategies for elimination, and provide valuable metrics for monitoring the success of control efforts, if population genetic parameters accurately reflect transmission intensity. However, the information of autochthonous $P$. vivax population in Hainan Province is limited.

The pvmsp-1 locus codes for a major asexual bloodstage antigen had extensive polymorphism in isolates from different geographical regions. Three allele types including Belem, Sal-1, and recombinant variable block 5 have been found in isolates of $P$. vivax worldwide. The pvmsp-1 markers have been used in genetic studies of $P$. vivax in many countries, including India, Myanmar, Brazil, Latin America, and Korea [10,12,19,20]. In 2003, this marker was used for investigating 33 samples collected from various sites of $P$. vivax endemic areas in mainland China [21]. The result of this investigation showed that three allele types were found in China and that Sal-1 and recombinant allelic types were dominant, although the frequency of those types were different in different areas. In Hainan, three allele types were found and some sample had two allele types in 2002 and 2005 $[21,22]$. In the present study, three allele types were detected among the Hainan isolates, with the Sal-1 type being the predominant one. A similar degree of diversity was also found in Hainan Province in 2002 and 2005 $[21,22]$. Since 2003, some new subtypes have been found according to their amino acid sequences. In present study, the sequence of amino acid of pvmsp-1 was longer than most published sequences and most of subtypes were similar with other stains in phylogeny tree of pvmsp-1. Only subtype F and subtype I showed 100\% identity with AAR30523 and AAR30526 strains isolated from Hainan in 2003, respectively. Comparison with published sequences, some of subtypes had single amino acid inserted or deleted or substituted and became new subtypes. Furthermore, Sal subtype I from Hainan isolates had some similarity with the subtype $\mathrm{K}$ and the subtype L, which were collected from Myanmar [12]. Those isolates were contained the amino acid sequence MKKELLDQYK specific to the Sal 1 type rather than the DKKLLKEYE specific to the Belem type. This kind of isolate was first reported in China.

Currently, $p v c s p$ acts as an important gene marker and it has been used successfully in epidemiological studies of $P$. vivax malaria. This marker has two types: classic type (VK210) and variant type (VK247); the former, is known as classic type with obvious character of repeat motif as GDRAA/DGQPA within the amino acid tandem repeat region whereas, the latter is known as variant type with ANGAGNQPG amino acid repeats within the amino acid tandem repeat region. These two types have a worldwide distribution [23,24]. VK210 has been observed as predominant type in many countries, although VK247 was reported to be the predominant type previously [25-28]. In 2001, 384 samples were collected from 10 vivax-endemic provinces and the results showed that both types of csp genes were observed and that VK210 was the dominant type [29]. Since then, many research devote to investigate the ratio of two types in different regions of China but VK247 and mixed infections also have only been found in south China, including Yunnan Province and Hainan Province [30,31]. Moreover, in other endemic areas, including Anhui, Hubei, Guangxi, Guizhou, Guangdong, there was only the 
VK210 type. In present study, VK210 and VK247 still exist in Hainan but there were no mixed infections. The ratio between VK210 and VK247 decreased from 87:12 in control malaria stage in 2002 to $23: 4$ in elimination stage of present study [30]. There are no statistical differences between these data $\left(\chi^{2}=0.747, d f=1, \mathrm{P}>0.05\right)$. The changes of ratio of two types of csp have influenced the decrease of malaria cases in Hainan Province. There is limited information concerning the sequence of the subtypes in the two types of pvcsp from China. Comparison with published sequences in NCBI and nearby sequences from phylogeny trees of $p v c s p$, most of subtypes were new alleles because they had different numbers of repeat motif or had different mutations in motif, except subtype C was showed 100\% identity with AAV80840 strains isolated from Mauritania in 2004.

$p v m s p-3 \alpha, p v m s p-3 \beta$ and $p v m s p-3 \gamma$ are members of a multi-allelic diversifying selection to fit the evolution $[31,32]$. This gene family exhibits a high degree of genetic diversity but $p v m s p 3$ may be analogous with $p f m s p 3$, not homologous [31]. The PCR-RFLP method has been applied for analysing the degree of diversity in $p v m s p-3 \alpha$ and $p v m s p-3 \beta$ over many years $[33,34]$, but this method has recently been suspected not to be suitable for broad geographic studies or tracking parasite populations [33]. The larger sample showed that some of identical haplotypes could be produced from analogous bands after PCR-RFLP analysis and revealed incongruence between the observed levels of nucleotide polymorphism and the pattern of PCR-RFLP haplotype [33].

Based on the length of PCR products, allelic type A and allelic type $\mathrm{B}$ of $p v m s p-3 \alpha$ have been detected among the 27 tested isolates. The observation was different from a previous report from several locations in China, in which type A, B, C, and mixed infection were detected in $P$. vivax isolates from Sanya city of Hainan Province $[7,35]$. The lack of type $C$ allele types in the present study could be due to a disappearance of this allele before implementation of the NMEP. Taking consideration of frequency of genotype, type $\mathrm{A}$ had a high frequency $(96 \%, 26 / 27)$ and was a predominant type at elimination stage of malaria in Hainan Province. The present study results are consistent with previously published reports indicating type $\mathrm{A}$ as the most prevalent type around the world with a frequency 70 to $100 \%$ (average $\sim 80 \%$ ) in many regions of China and countries of Asia and South America [7,11,13,34].

In the analysis of pvmsp-3 $\alpha$, PCR-RFLP allele types and frequencies, 11 patterns were detected in the pvmsp- $3 \alpha$ gene after digestion of the PCR products with Hha I, and the most frequent allele variant were $\mathrm{H} 1$ and H3 subtypes. The Hha I allelic types, including H1, H3, H4, H5 H6, H7, H8, H10, and H11 were found. Those Hha I allelic types had been found in other regions of
China and in parts of the world. Similarly, variants H1, $\mathrm{H} 3, \mathrm{H} 5, \mathrm{H} 7$, and $\mathrm{H} 10$ were found in Myanmar [7]. The variants, including $\mathrm{H} 4, \mathrm{H} 6$, and $\mathrm{H} 11$ isolated in the present study, have high similarity with variants A3, A6 and A4 isolated in Thailand [36], respectively. Variant $\mathrm{H} 8$ has extensive similarity with variant A6 isolated in Brazil. In China, variants $\mathrm{H} 1, \mathrm{H} 3, \mathrm{H} 6, \mathrm{H} 7$, and $\mathrm{H} 10$ were reported earlier in Hainan Province [7] and allelic variants $\mathrm{H} 4$ and $\mathrm{H} 11$ were also identified in Anhui Province [35]. Others variants, including A9 and A11, were found only in Anhui Province. Moreover, variants A2, A3, A5, and $\mathrm{A} 10$ were not found in present study. However, new allelic variants $\mathrm{H} 2$ and $\mathrm{H} 9$ have been reported in the present study, which were not described in previous reports.

Nine patterns were detected in the Pvmsp-3 $\alpha$ gene after digestion of PCR products with Alu I, with PA1 pattern being the predominant in Hainan Province at the elimination stage of malaria. Some allele types of $\mathrm{Alu}$ I digestion are comparable to those reported in other parts of the world, such as allele types A2, A3, A4, and A5 isolated in Anhui Province of China [35], types A1, A2, A3, A4, A5, and A8 in Pakistan [11], types A1, A2, A3, A4, and A5 in Iran [37], and types A1, A2, and A5 in Colombia [38], which suggests that these allele types of $P$. vivax may have a global distribution. The allele variant B1 was a new allele identified in the present study. The analysis of Pvmsp-3 $\alpha$ gene marker suggested that $P$. vivax populations in Hainan Province showed diversity at elimination stage of malaria and shared the majority of allelic variants with other parts of China and the world.

pvmsp-3 $\beta$ gene encodes merozoite surface protein dominated by alanine-rich central domains, which is strongly predicted to form a coil-like tertiary structure. The structure of central domain is radically divergent with the majority bearing large insertion/deletion mutations and it has been employed as a molecular marker to evaluate genetic diversity of $P$. vivax. Only type A and type $\mathrm{B}$ alleles were detected among four types of alleles in $p v m s p-3 \beta$ marker at the elimination stage of malaria, with type A being more abundant (62.9\%) than type B. In comparison with previous study on $P$. vivax isolates from Hainan Province in 2006 [7], the multiple genotypes of $p v m s p-3 \beta$ marker have been decreased from four to two types. In addition, in the present study, RFLP analysis revealed different allelic compositions and a total of nine alleles were identified. Interestingly, despite the differences in geographic regions, some allele types of Pst I digestion were comparable to those reported in other parts of the world, such as allele types PA1, PA3, PB1, and PB2 isolated in China and Myanmar [7], type PA5 in Pakistan [15], types PA2, PA3, PB1, and PB2 in China and Thailand [35], suggesting that these allele 
types of $P$. vivax may have a global distribution. In the present study, new allele variants PA1, PA4, PA5, PB3, and $\mathrm{PM}$ were identified. The levels of mixed-genotype infections were correlated with the levels of endemicity and the power of sensitivity on selected gene marker. The discrimination of $p v m s p-3 \beta$ gene marker for mixedgenotype infections in several endemic regions has more sensitivity than other markers, especially in endemicity; for example, genotyping the Thai samples for $p v m s p-3 \beta$ detected $20.5 \%$, whereas combination with genotyping pvmsp-3 $\alpha$ increased the mixed infection level to $29.5 \%$ [33]. On the other hand, genetic diversity of the malarial parasites is associated with the levels of endemicity and transmission intensity [15]. In hyperendemic areas, such Myanmar [12], and Thailand [39], P. vivax is highly diverse with multiplicity of infections. However, in Korea and Iran $[23,40], P$. vivax was resurgent, and mixed infections were detected; however, the infection proportion was very low. In the present study, mixed infection was still detected by pvmsp-3 $\beta$ at the elimination stage of malaria. This information could suggest that the genetic diversity of the malaria parasites is not only associated with the levels of endemicity and transmission intensity, but could also be associated with epidemic times in history.

$p v m s p-3 \alpha$ and $p v m s p-3 \beta$ are promising markers for epidemiological applications. Compared with the simple PCR-RFLP method, sequencing of these markers may offer significantly higher power for determining parasite genetic diversity. Analysis of diversity in $p v m s p-3 \alpha$ and $p v m s p-3 \beta$ by sequencing opens new perspectives for diversity analysis and this method had been used at the Thai-Myanmar border area and revealed that the extent of allelic diversity in $P$. vivax populations in Thailand [41].

\section{Conclusion}

The present study indicates that there was still a high degree of genetic diversity of P. vivax in Hainan Province at the pre-elimination stage, with 26 unique haplotypes observed among 27 samples, inferring that $P$. vivax populations are more resilient to elimination, compared to Solomon Islands and Thai-Myanmar border areas.

\section{Competing interests}

The authors declare that they have no competing interests.

\begin{abstract}
Authors' contributions
$\mathrm{YL}$ and GW were involved in the conceptualization, design, execution and first draft manuscript. WZ, FM and CH collected samples and investigation. SW and XH contributed to consulting, data analysis and interpretation of the results. All authors were involved in the preparation of the manuscript. All authors read and approved the final manuscript.
\end{abstract}

\section{Acknowledgements}

This study received a financial support from the Hainan Provincial Scientific Research (Grant no. 310174 and 813251).
Received: 7 November 2014 Accepted: 5 January 2015

Published online: 14 February 2015

\section{References}

1. Guerra CA, Snow RW, Hay SI. Mapping the global extent of malaria in 2005. Trends Parasitol. 2006;22:353-8.

2. Mendis K, Sina BJ, Marchesini P, Carter R. The neglected burden of Plasmodium vivax malaria. Am J Trop Med Hyg. 2001;64(1-2 Suppl):97.

3. Tang LH. [Chinese achievements in malaria control and research] (in Chinese). Chin J Parasitol Parasit Dis. 1999;17:257.

4. Tang LH. [Malaria in China: from control to elimination] (in Chinese). Int J Med Parasit Dis. 2009;36:258-85.

5. Xia ZG, Yang MN, Zhou SS. [Malaria situation in the People's Republic of China in 2011] (in Chinese). Chin J Parasitol Parasit Dis. 2012;30:419-22.

6. Zhou SS, Wang Y, Li Y. [Malaria situation in the People's Republic Of China in 2010] (in Chinese). Chin J Parasitol Parasit Dis. 2011;29:401-3.

7. Zhong D, Bonizzoni M, Zhou G, Wang G, Chen B, Vardo-Zalik A, et al. Genetic diversity of Plasmodium vivax malaria in China and Myanmar. Infect Genet Evol. 2011;11:1419-25.

8. Xiao D, Long Y, Wang S, Fang L, Xu D, Wang G, et al. Spatiotemporal distribution of malaria and the association between its epidemic and climate factors in Hainan. China Malar J. 2010;9:185.

9. Li Y, Wang G, Sun D, Meng F, Lin S, Hu X, et al. A case of Plasmodium ovale wallikeri infection in a Chinese worker returning from West Africa. Korean J Parasitol. 2013;51:557.

10. Choi YK, Choi KM, Park MH, Lee EG, Kim YJ, Lee BC, et al. Rapid dissemination of newly introduced Plasmodium vivax genotypes in South Korea. Am J Trop Med Hyg. 2010;82:426-32.

11. Khatoon L, Baliraine FN, Bonizzoni M, Malik SA, Yan G. Genetic structure of Plasmodium vivax and Plasmodium falciparum in the Bannu district of Pakistan. Malar J. 2010;9:112.

12. Moon S, Lee H, Kim J, Na B, Cho S, Lin K, et al. High frequency of genetic diversity of Plasmodium vivax field isolates in Myanmar. Acta Trop. 2009;109:30-6.

13. Véron V, Legrand E, Yrinesi J, Volney B, Simon S, Carme B. Genetic diversity of msp3a and msp1_b5 markers of Plasmodium vivax in French Guiana. Malar J. 2009:8:40.

14. Bonilla JA, Validum L, Cummings R, Palmer CJ. Genetic diversity of Plasmodium vivax pvcsp and pvmsp1 in Guyana, South America. Am J Trop Med Hyg. 2006;75:830-5.

15. Yang Z, Miao J, Huang Y, Li X, Putaporntip C, Jongwutiwes S, et al. Genetic structures of geographically distinct Plasmodium vivax populations assessed by PCR/RFLP analysis of the merozoite surface protein 3beta gene. Acta Trop. 2006;100:205-12.

16. Xia ZG, Yang MN, Zhou SS. Malaria situation in the People's Republic of China in 2011. Chin J Parasitol Parasit Dis. 2012;6:419-22.

17. Zhou SS, Wang Y, Li Y. Malaria situation in the People's Republic of China in 2010. Chin J Parasitol Parasit Dis. 2011;6:401-3.

18. Xia ZG, Feng J, Zhou SS. Malaria situation in the People's Republic of China in 2012. Chin J Parasitol Parasit Dis. 2013;6:413-8.

19. González-Cerón L, Martinez-Barnetche J, Montero-Solís C, Santillán F, Soto AM, Rodríguez MH, et al. Molecular epidemiology of Plasmodium vivax in Latin America: polymorphism and evolutionary relationships of the circumsporozoite gene. Malar J. 2013;12:243.

20. Santos-Ciminera PD, Alecrim MDGC, Roberts DR, Quinnan GV. Molecular epidemiology of Plasmodium vivax in the State of Amazonas, Brazil. Acta Trop. 2007;102:38-46.

21. Jiang GF, Li JL, WU ST, Wang SQ. Genotyping and sequence analysis of Pvmsp1 of Plasmodium vivax isolates from China. Chin J Zoonoses. 2002;2:57-60.

22. Zhang SY, Lu HM, Xu LS, Gao Q, Shen YZ, Huang WD. Polymorphism analysis of Plasmodium vivax merozoite surface protein 1 (PvMsp- 1) gene from different malaria-endemic area of China. Chin J Zoonoses. 2004; 1:26-30.

23. Zakeri S, Abouie MA, Djadid ND, Snounou G. Circumsporozoite protein gene diversity among temperate and tropical Plasmodium vivax isolates from Iran. Trop Med Int Health. 2006;11:729-37.

24. Gonzalez JM, Hurtado S, Arevalo-Herrera M, Herrera S. Variants of the Plasmodium vivax circumsporozoite protein (VK210 and VK247) in Colombian isolates. Mem Inst Oswaldo Cruz. 2001;96:709-12.

25. Kain KC, Brown AE, Webster HK, Wirtz RA, Keystone JS, Rodriguez MH, et al. Circumsporozoite genotyping of global isolates of Plasmodium vivax from dried blood specimens. J Clin Microbiol. 1992;30:1863-6. 
26. Lopez AC, Ortiz A, Coello J, Sosa-Ochoa W, Torres R, Banegas El, et al. Genetic diversity of Plasmodium vivax and Plasmodium falciparum in Honduras. Malar J. 2012;11:391.

27. Kim JR, Imwong M, Nandy A, Chotivanich K, Nontprasert A, Tonomsing N, et al. Genetic diversity of Plasmodium vivax in Kolkata. India Malar J. 2006:5:71.

28. Kim TS, Kim HH, Lee SS, Na BK, Lin K, Cho SH, et al. Prevalence of Plasmodium vivax VK210 and VK247 subtype in Myanmar. Malar J. 2010;9:195.

29. Huang TY, Huang YM, Wang XL, Li XM, Zhang ZX, Wang SQ, et al. Investigation on genotype constitution of different Plasmodium vivax isolates and its geographical distribution in China. Chin J Parasitol Parasit Dis. 2001:5:4-8.

30. Wang GZ, Huang D, Wang SQ, Lin CF, Lin SG, Lan HX, et al. Identification of circumsporozoite protein genes of Plasmodium vivax and distribution of geographic in Hainan province. Chin J Parasitol Parasit Dis. 2001;3:19-21.

31. Rice BL, Acosta MM, Pacheco MA, Carlton JM, Barnwell JW, Escalante AA. The origin and diversification of the merozoite surface protein 3 (msp3) multi-gene family in Plasmodium vivax and related parasites. Mol Phylogenet Evol. 2014;78:172-84.

32. Rice BL, Acosta MM, Pacheco MA, Escalante AA. Merozoite surface protein-3 alpha as a genetic marker for epidemiologic studies in Plasmodium vivax: a cautionary note. Malar J. 2013;12:288.

33. Cui L, Escalante AA, Imwong M, Snounou G. The genetic diversity of Plasmodium vivax populations. Trends Parasitol. 2003;19:220-6.

34. Bruce MC, Galinski MR, Barnwell JW, Snounou G, Day KP. Polymorphism at the merozoite surface protein-3alpha locus of Plasmodium vivax: global and local diversity. Am J Trop Med Hyg. 1999;61:518-25.

35. Huang B, Huang S, Su XZ, Guo H, Xu Y, Xu F, et al. Genetic diversity of Plasmodium vivax population in Anhui province of China. Malar J. 2014;13:13.

36. Cui L, Mascorro CN, Fan Q, Rzomp KA, Khuntirat B, Zhou G, et al. Genetic diversity and multiple infections of Plasmodium vivax malaria in western Thailand. Am J Trop Med Hyg. 2003;68:613-9.

37. Zakeri S, Barjesteh H, Djadid ND. Merozoite surface protein-3 a is a reliable marker for population genetic analysis of Plasmodium vivax. Malar J. 2006:5:53.

38. Cristiano FA, Perez MA, Nicholls RS, Guerra AP. Polymorphism in the Plasmodium vivax msp 3: gene in field samples from Tierralta, Colombia. Mem Inst Oswaldo Cruz. 2008;103:493-6.

39. Imwong M, Nair S, Pukrittayakamee S, Sudimack D, Williams JT, Mayxay M, et al. Contrasting genetic structure in Plasmodium vivax populations from Asia and South America. Int J Parasitol. 2007;37:1013-22.

40. Han ET, Song TE, Park JH, Shin EH, Guk SM, Kim TY, et al. Allelic dimorphism in the merozoite surface protein-3alpha in Korean isolates of Plasmodium vivax. Am J Trop Med Hyg. 2004;71:745-9.

41. Putaporntip C, Miao J, Kuamsab N, Sattabongkot J, Sirichaisinthop J, Jongwutiwes $S$, et al. The Plasmodium vivax merozoite surface protein $3 \beta$ sequence reveals contrasting parasite populations in Southern and Northwestern Thailand. PLoS Negl Trop Dis. 2014;8:e3336.

\section{Submit your next manuscript to BioMed Central and take full advantage of:}

- Convenient online submission

- Thorough peer review

- No space constraints or color figure charges

- Immediate publication on acceptance

- Inclusion in PubMed, CAS, Scopus and Google Scholar

- Research which is freely available for redistribution 